\title{
Pengaruh Budaya dan Lokasi Terhadap Persepsi dan Penggunaan Telefon Bimbit di Tempat-Tempat Awam: Satu Analisis Perbandingan Antara Beberapa Negara
}

\author{
Siti Harnani Amir Hushin, Hasrina Mustafa*, Bahiyah Omar
}

School of Communication, Universiti Sains Malaysia, 11800 Penang

*Corresponding author: hasrina@usm.my

\begin{abstract}
This study aims to compare the level of perception of using mobile phones at public places among users of four different countries; Malaysia, Indonesia, China and Iran from the perspective of Social Interaction Theory. A survey was conducted on 100 university students from each country that makes up a sample of 400 respondents. The findings of the study show 1) a significant difference in the perception of mobile phone and SMS usage in public places among respondents from different countries. Unlike Malaysian, Indonesian and Chinese respondents, the results of the study show that Iranian respondents are not too disturbed by the usage of mobile phones at public places. 2) The study also finds that Malaysian and Indonesian respondents seldom use mobile phone in public places, and that Chinese respondents often use mobile phone in public transport (i.e: bus). Meanwhile, Iranian respondents use mobile phone the most in four identified places - the supermarket, bus, pedestrian walkway and restaurant. 3) Most of the respondents in each category, however, prefer to use mobile phone - for making calls and SMS - in multi focused gathering compared to fully focused ones. The study concludes that cultural and geographical factors exert significant influence on the usage and perception of using mobile phone at public places.
\end{abstract}

Keyword: Social Interaction Theory, mobile phone, multi-focused gathering, fully focused gathering

Abstrak

Kajian ini bertujuan untuk mengkaji persepsi dan penggunaan telefon bimbit dan khidmat pesanan ringkas di tempat awam yang melibatkan responden dari empat negara iaitu Malaysia, Indonesia, China dan Iran. Kajian ini menggunakan Teori Interaksi Sosial oleh Goffman (1959) dalam memahami isu yang dikaji. Kaedah tinjauan menggunakan borang soal selidik berstruktur dalam kalangan 400 responden yang terdiri 100 pelajar dari Malaysia, 100 pelajar dari Indonesia, 100 pelajar dari China dan 100 pelajar lagi dari Iran telah dijalankan. Dapatan kajian menunjukkan: 1) Terdapat perbezaan yang signifikan di antara responden di kalangan negara yang berbeza mengenai persepsi terhadap penggunaan telefon bimbit dan khidmat pesanan ringkas di tempat-tempat awam, di mana responden Malaysia, Indonesia dan China paling berasa terganggu di tempat-tempat awam, manakala responden Iran paling kurang terganggu di tempat-tempat awam 2) Terdapat perbezaan yang signifikan di antara responden di kalangan negara yang berbeza dalam penggunaan telefon bimbit dan khidmat pesanan ringkas di tempat-tempat awam, di mana responden Malaysia dan Indonesia merupakan pengguna yang paling jarang, menggunakan telefon bimbit di semua tempat-tempat awam manakala responden dari China kerap menggunakan telefon bimbit di dalam bas sahaja Responden Iran adalah pengguna paling kerap di empat tempat iaitu pasaraya, bas, laluan pejalan kaki dan restoran. 3) Kebanyakan responden dari pelbagai negara lebih kerap menggunakan telefon bimbit dan khidmat pesanan ringkas di tempat tumpuan pelbagai berbanding tempat tumpuan fokus. Kajian merumuskan bahawa fakor kedekatan budaya dan lokasi didapati mempengaruhi persepsi dan penggunaan telefon bimbit dan khidmat pesanan ringkas di tempat-tempat awam.

Kata kunci: Teori Interaksi Sosial, persepsi, telefon bimbit, tempat tumpuan pelbagai, tempat tumpuan berfokus.

(C) 2018 Penerbit UTM Press. All rights reserved

\subsection{PENGENALAN}

Telefon bimbit adalah satu alat komunikasi yang cukup penting pada hari ini. Laporan yang dikeluarkan oleh Suruhanjaya Komunikasi Dan Multimedia (SKMM) pada tahun 2015 menunjukkan langganan rangkaian telefon bimbit di Malaysia adalah sebanyak 43.3 juta dengan kadar penetrasi sebanyak 144.2 bagi setiap 100 pelanggan. Kebanyakan pengguna telefon bimbit merupakan golongan muda yang berumur di antara 20 hingga 29 tahun (35.1\%). Golongan ini merupakan kumpulan terbesar pengguna telefon bimbit di Malaysia, manakala kumpulan terkecil adalah golongan yang berumur 65 tahun ke atas iaitu sebanyak 2.3 peratus. Kajian juga mendapati 53.4 peratus daripada jumlah keseluruhan pengguna merupakan pelanggan telefon pintar dan dari jumlah ini sebanyak 63.3 peratus pengguna mengakses Internet melalui telefon pintar mereka (SKMM, 2015).

Peningkatan pengguna telefon bimbit secara konsisten telah menyebabkan media baru ini membentuk budaya baru dalam masyarakat di samping memberi implikasi sosial terhadap masyarakat (Campbell,2007a; Caporeal \& Xie, 2003; Fortunati, 2003). Seperti 
media terdahulu seperti televisyen dan radio, penggunaan telefon bimbit yang begitu meluas, telah membentuk budaya tersendiri dalam kalangan penggunanya. Tidak seperti telefon tetap yang terhad penggunaannya di rumah ataupun di pejabat, penggunaan telefon bimbit menjangkaui lokasi yang lebih luas dan umum seperti di cafeteria, rumah ibadat, lorong pejalan kaki dan stesyen bas menyebabkan timbul isu sama ada penggunaan media interpersonal ini mengganggu privasi umum. Justeru itu kajian ini cuba melihat dan menilai persepsi dan penggunaan telefon bimbit di tempat-tempat awam dan cuba membandingkan amalan ini dalam kalangan responden dari beberapa negara berbeza.

\subsection{ASAS TEORITIKAL KAJIAN}

Kajian ini menggunakan Teori Interaksi Sosial yang dibangunkan oleh Erving Goffman pada tahun 1959 dalam memahami penggunaan telefon bimbit di tempat-tempat awam. Teori ini merupakan sebuah teori yang sangat luas, mempunyai pelbagai cabang dan sangat fleksibel. Interaksi sosial menurut Goffman (1959) bermaksud satu proses di mana dua atau lebih aktor sosial saling mempengaruhi satu sama lain, dan merupakan satu proses penting yang menghubungkan individu dengan masyarakat. Goffman (1959) yang menyatakan bahawa interaksi adalah sebuah persembahan yang dibantu oleh persekitaran dan audien untuk membentuk satu tanggapan seperti yang diharapkan oleh pelakon. Goffman (1959) menggunakan metafora dramaturgikal untuk menjelaskan proses interaksi sosial. Metafora ini menyamakan proses interaksi sosial dengan sebuah pentas teater, di mana individu yang berada di tempat awam ialah seorang aktor/pelakon yang perlu melakonkan watak, mementaskan situasi dan bertindak mengikut naratif sosial (Goffman, 1959). Proses ini memerlukan seseorang individu atau aktor sosial tersebut mengimbangi pentas hadapan iaitu 'penonton yang sedang menonton' dan 'aktiviti yang sedang dilakukan' dan pentas belakang iaitu 'perkara yang ingin disorok daripada orang lain' (Goffman, 1959). Dalam hal ini, seorang pengguna telefon bimbit yang menggunakan medium ini di tempat awam seperti di stesyen bas, sebenarnya terpaksa mengimbangi aktivitinya di dua pentas iaitu pentas belakang dan pentas hadapan. Dalam konteks ini pentas belakang adalah orang ramai yang menjadi pendengar tidak rasmi di stesyen bas, manakala pentas hadapan merujuk kepada individu yang menelefonnya atau sedang berinteraksi dengannya.

Tahap gangguan penggunaan telefon bimbit di tempat awam bergantung kepada jenis situasi/lokasi. Goffman (1963) membahagikan situasi/lokasi tempat awam kepada kepada dua iaitu situasi interaksi berfokus dan situasi interaksi tidak berfokus. Maksud fokus dalam konsep Goffman adalah merujuk kepada tahap penglibatan seseorang individu dalam sesuatu persekitaran. Dalam lokasi interaksi berfokus, semua 'pelakon' sama-sama terlibat antara satu dengan lain. Dalam situasi ini, tahap penglibatan individu adalah tinggi di samping fokus terhadap aktiviti yang sedang berlangsung. Contohnya semasa mesyuarat di mana tumpuan diberikan sepenuhnya kepada isu yang dibincangkan. Persekitaran ini ialah lokasi 'fully focused'. Interaksi tidak berfokus pula melibatkan orang-orang sekeliling (bystanders) yang turut berada di tempat tersebut. Individu tersebut tidak terlibat dalam aktiviti yang sedang berlangsung dan hanya separa fokus. Situasi ini dipanggil persekitaran 'multi-focused'.

Dalam hal ini, penggunaan telefon bimbit yang dalam situasi yang "fully focused" seperti di dewan kuliah dan rumah ibadat dianggap akan paling mengganggu orang ramai kerana mereka sedang menumpukan aktiviti mereka kepada satu aktiviti yang sama iaitu mendengar kuliah. Walau bagaimanapun, penggunaan telefon bimbit di tempat/lokasi multi-focused seperti di laluan pejalan kaki dan kafetaria dianggap kurang mengganggu kerana orang ramai sedang melakukan aktiviti mereka tersendiri seperti makan atau mendengar radio. Goffman $(1963,1971)$ turut menghuraikan dengan lebih mendalam proses interaksi sosial dengan menggunakan istilah 'singles' dan 'withs'. Goffman (1971) menjelaskan mayarakat yang berada di tempat awam kepada dua kumpulan iaitu 'singles', iaitu individu yang bersendirian, dan 'withs', iaitu individu yang bersama dengan individu lain. Individu yang bersendirian akan berasa lebih terganggu apabila mendengar perbualan telefon bimbit orang lain, berbanding individu yang bersama teman kerana mereka mungkin kurang fokus kepada bunyi teleofn bimbit yang berlaku.

Dalam konteks kajian ini, Teori Interaksi Sosial diaplikasikan bagi memahami secara lebih mendalam, norma perlakuan manusia dalam berinteraksi secara sosial melalui penggunaan telefon bimbit di tempat awam. Penggunaan telefon bimbit di tempat awam perlu dilihat dengan lebih mendalam kerana ia menyentuh etika dan norma masyarakat. Teori Interaksi Sosial membantu penyelidik memahami tingkah laku penggunaan telefon bimbit di tempat awam dalam persekitaran awam yang berbentuk lokasi tumpuan penuh "fully focused" dan lokasi tumpuan pelbagai atau "multi-focused". Teori ini mampu memberikan penjelasan kenapa tingkah laku penggunaan telefon bimbit ini berbeza di pelbagai persekitaran awam melalui konsep "pentas hadapan" dan "pentas belakang".

Seterusnya, tidak dapat dinafikan bahawa faktor negara dan budaya yang berbeza turut mempengaruhi tahap di mana seorang individu berasa terganggu ataupun tidak dengan deringan dan perbualan telefon bimbit di tempat awam. Bagi sesetengah negara atau budaya, deringan telefon bimbit di bank, dianggap begitu tidak sopan dan menjengkelkan. Walau bagaimanapun, di negara lain, situasi yang sama, mungkin boleh diterima. Goffman (1963) menyatakan bahawa penglibatan dalam interaksi sosial memerlukan konsensus dan definisi kolektif terhadap sesuatu situasi. Konsensus dan definisi kolektif tersebut mungkin berbeza dalam negara atau budaya yang berbeza (Goffman, 1963). Hall (1959) turut bersetuju bahawa budaya memainkan peranan yang penting di dalam kehidupan seseorang individu kerana ianya mempengaruhi cara pembawaan diri individu dan cara individu menyesuaikan diri dengan realiti kehidupan. Oleh itu, boleh dikatakan bahawa budaya boleh mempengaruhi persepsi dan tingkah laku seseorang individu, termasuklah terhadap penggunaan telefon bimbit.

\subsection{KERANGKA KONSEP}

Kajian ini melihat perhubungan antara faktor budaya dan lokasi sebagai pembolehubah bebas manakala persepsi dan penggunaan telefon bimbit di tempat-tempat awam sebagai pembolehubah bersandar. 
Pengaruh Budaya Terhadap Persepsi Dan Penggunaan Telefon Bimbit Di Tempat Awam

Penggunaan telefon bimbit bukanlah sesuatu yang baru di kebanyakan negara, oleh sebab itu akan terdapat pengguna yang sering menggunakan telefon bimbit di tempat awam. Secara perlahan-lahan pengguna telefon bimbit ini mempengaruhi pengguna telefon bimbit lain dan akhirnya membawa kepada persepsi dan tabiat yang agak sama terhadap penggunaan telefon bimbit di tempat awam. Campbell dalam kajiannya mendapati tiada perbezaan yang ketara ke atas persepsi penggunaan telefon bimbit di tempat awam di kalangan pengguna telefon bimbit dari Amerika Syarikat, Jepun, Taiwan, New Zealand dan Sweden (Campbell, 2007a). Ianya disokong oleh kajian daripada Katz dan Aakhus (dipetik oleh Campbell, 2007a) yang menunjukkan terdapat persamaan daripada aspek tabiat berkomunikasi yang berkait dengan penggunaan telefon bimbit di tempat awam di kalangan individu-individu dari negara Finland, Israel, Itali, Korea, Amerika Syarikat, Perancis, Belanda dan Bulgaria.

Oleh yang demikian tidak hairanlah sekiranya Katz dan Aakhus (2007) mencadangkan perbezaan budaya di setiap negara sama sekali tidak mempengaruhi aplikasi dan penggunaan telefon bimbit di kalangan pemilik telefon bimbit di kebanyakan negara. Kajian yang di jalankan oleh Mante pada 2002 (dipetik oleh Campbel 2007a), turut mendapati terdapat persamaan di antara pengguna telefon bimbit dari Korea, Norway, Amerika Syarikat dan Namibia daripada segi sikap dan penggunaan telefon bimbit walaupun jarak geografi negaranegara yang dikaji adalah berjauhan di antara satu sama lain.

Ianya bagaimanapun tidak dipersetujui oleh Blom, Chicpase dan Lehikonen dalam artikel mereka yang dipetik oleh Nickersson, Issac dan Mak, (2008). Kajian mereka mendapati sikap pengguna telefon bimbit adalah berbeza di setiap negara. Mereka membuktikan bahawa persepsi penggunaan telefon bimbit di tempat awam di kalangan individu mungkin berbeza kerana individu dipengaruhi oleh latar belakang budaya di dalam sesebuah komuniti masyarakat.

Seperti kajian oleh Ling dan Haddon pada 2003 yang dipetik dari Campbell, (2007a), menunjukkan pemilik telefon bimbit dari negara Perancis, Jerman, Itali, Sepanyol dan Britain cenderung untuk memadamkan telefon bimbit mereka apabila berada di tempat larangan penggunaan telefon bimbit seperti di dalam pawagam dan dewan teater. Kajian berkaitan dengan penggunaan telefon bimbit yang dijalankan oleh Campbell ke atas orang awam yang berasal dari Amerika Syarikat, Kepulauan Hawaii, Jepun dan Sweden mendapati penggunaan telefon bimbit paling tidak boleh diterima di dalam pawagam dan ianya merupakan salah laku penggunaan telefon bimbit.

Akan tetapi, Campbell (2007a) mendapati pengguna telefon bimbit dari negara Taiwan boleh menerima dengan baik aktiviti penggunaan telefon bimbit di pawagam dan restoran. Begitu juga kajian yang dilakukan Chan, Vogel dan Ma (2007), mendapati orang awam di Hong Kong tidak menganggap penggunaan telefon bimbit di tempat awam seperti bercakap dengan kuat merupakan satu gangguan. Malah mereka juga tidak menganggap ianya sebagai satu perkara yang tidak bermoral atau sebagai tidak menghormati orang awam di sekeliling. Hal ini menunjukkan, masyarakat daripada budaya yang berbeza mempunyai persepsi yang berbeza mengenai penggunaan telefon bimbit di tempat awam dan mereka boleh menerima aktiviti penggunaan telefon bimbit di tempat awam kerana aktiviti itu bukan satu kesalahan mahupun satu gangguan kepada mereka.

\section{Pengaruh Lokasi Terhadap Persepsi Dan Penggunaan Telefon Bimbit}

Penggunaan telefon bimbit di tempat awam sering mengganggu orang lain yang berada di tempat tersebut. Individu yang menggunakan telefon bimbit di tempat awam lazimnya tidak berasa bersalah dan tetap menggunakan telefon bimbit walaupun menyedari ianya tidak sesuai untuk digunakan. Berdasarkan kajian yang dilakukan oleh Monk, Fellas dan Ley (2004), kebanyakan responden berpendapat penggunaan telefon bimbit di tempat awam adalah sesuatu yang menjengkelkan atau dengan kata lain menyakitkan mata dan telinga. Laporan daripada University of Michigan (2006) (dipetik oleh Campbell, 2008) menunjukkan 81\% orang dewasa di Amerika Syarikat tidak bersetuju dengan penggunaan telefon bimbit di tempat awam selain berpendapat ianya adalah salah laku masalah sosial yang semakin membimbangkan. Kajian yang dilakukan oleh Palen, Salzman dan Youngs pada tahun 2001 yang dipetik oleh Nickersson, Issac dan Mak, (2008) menunjukkan orang awam terganggu dengan penggunaan telefon bimbit disebabkan oleh konteks perbualan yang melibatkan penggunaan nada suara yang tinggi, bunyi nada dering yang ditetapkan pemilik lazimnya sangat kuat dan bising dan bunyi yang terhasil apabila kekunci telefon bimbit ditekan dianggap sangat mengganggu.

Dapatan kajian ini disokong oleh Sari, Ramli dan Budiarjo (2004) yang mendapati responden mereka menyatakan rasa tidak senang terhadap nada dering telefon bimbit di tempat awam yang sesak dan intonasi percakapan yang lebih kuat daripada biasa. Kajian oleh Love dan Kewly (2005) membuktikan penggunaan telefon bimbit di tempat awam telah mencetuskan konflik di antara pengguna telefon bimbit dan individu di sekitarnya. Walaupun konflik ini tidak berlaku secara fizikal, orang awam didapati terganggu dan tidak selesa apabila terpaksa menjadi pendengar kedua kepada perbualan telefon bimbit yang berlaku di tempat awam.

Plant (2001) mencadangkan tiga jenis sikap yang akan dipamerkan oleh pemilik telefon bimbit di tempat awam iaitu 1. meninggalkan situasi sosial yang sedang berlaku untuk menjawab panggilan (flight); atau 2. kekal di dalam situasi sosial tetapi pada masa yang sama perhatian ditumpukan kepada konteks perbualan menerusi telefon bimbit (suspension) atau 3. kekal di dalam situasi sosial dan mengabaikan aktiviti yang melibatkan telefon bimbit (persistence).

Faktor lokasi memang memainkan peranan penting dalam mempengaruhi persepsi dan penggunaan telefon bimbit. Kajian Campbell (2007a) mendapati bahawa masyarakat lebih berpotensi untuk menolak penggunaan telefon bimbit di dalam kelas atau pawagam (fully focused gathering) berbanding tempat seperti restoran (multi focused gathering). Hasil kajian daripada Campbell ini telah menunjukkan orang ramai ternyata tidak selesa dengan penggunaan telefon bimbit di tempat-tempat di atas tetapi terpaksa menerimanya sekiranya ia berlaku. Kajian turut mendapati bahawa penggunaan telefon bimbit di dalam kelas, rumah ibadat dan restoran dianggap sangat mengganggu manakala penggunaan telefon bimbit di dalam pengangkutan awam, di jalanan dan kompleks membeli belah pula dianggap sebagai perlakuan yang langsung tidak boleh diterima (Wei \& Leung, 1999). Caporeal dan Xie (2003) pula melaporkan bahawa pengguna telefon bimbit lebih cenderung untuk mematikan telefon bimbit atau sekurang-kurang mengubah kepada mod senyap di lokasi-lokasi seperti dewan teater, rumah ibadat dan bilik mesyuarat.

Walaupun secara amnya penggunaan telefon bimbit di tempat awam kerap mengundang persepsi negatif, terdapat perbezaan dalam persepsi yang ditunjukkan terhadap penggunaan telefon bimbit untuk membuat atau menerima panggilan dan menghantar atau menerima khidmat pesanan ringkas di tempat awam. Kajian daripada Nickersson, Issac dan Mak (2008) menunjukkan aktiviti bercakap menggunakan telefon bimbit di tempat awam adalah lebih mengganggu orang awam di sekeliling berbanding dengan aktiviti menggunakan 
khidmat pesanan ringkas di tempat awam. Manakala kajian terhadap pelajar-pelajar di Jepun mendapati bahawa, aktiviti menghantar dan menerima khidmat pesanan ringkas semasa proses pembelajaran sebagai boleh diterima berbanding aktiviti membuat dan menerima panggilan menerusi telefon bimbit pada waktu pembelajaran (Ito dan Okabe 2005). Ini menunjukkan bahawa masyarakat lebih bertolak ansur terhadap penggunaan telefon bimbit untuk menghantar dan menerima khidmat pesanan ringkas berbanding untuk membuat dan menjawab panggilan telefon bimbit di tempat awam.

\section{Pernyataan Hipotesis}

Berdasarkan kepada sorotan literatur, maka hipotesis yang telah dikenalpasti adalah seperti berikut:

H1: Persepsi terhadap penggunaan telefon bimbit di tempat-tempat awam adalah berbeza di antara pengguna daripada budaya berbeza (Malaysia, Indonesia, China dan Iran).

H2: Persepsi penggunaan khidmat pesanan ringkas di tempat-tempat awam adalah berbeza di antara pengguna daripada budaya berbeza (Malaysia, Indonesia, China dan Iran).

H3: Penggunaan telefon bimbit di tempat-tempat awam adalah berbeza di antara pengguna daripada budaya berbeza (Malaysia, Indonesia, China dan Iran).

H4: Penggunaan khidmat pesanan ringkas di tempat-tempat awam adalah berbeza di antara pengguna daripada budaya berbeza (Malaysia, Indonesia, China dan Iran).

H5: Terdapat perbezaan persepsi terhadap penggunaan telefon bimbit di antara tempat yang melibatkan tumpuan sepenuhnya (fully focus gathering) (pawagam, kulian/kelas, bank dan rumah ibadat) dengan tempat tumpuan pelbagai (multi focus gathering) (restoran, laluan pejalan kaki, pengangkutan awam dan pasaraya).

H6: Terdapat perbezaan persepsi terhadap penggunaan khidmat pesanan ringkas di antara tempat yang melibatkan tumpuan sepenuhnya (fully focus gathering) (pawagam, kulian/kelas, bank dan rumah ibadat) dengan tempat tumpuan pelbagai (multi focus gathering) (restoran, laluan pejalan kaki, pengangkutan awam dan pasaraya).

H7: Terdapat perbezaan penggunaan telefon bimbit di antara tempat yang melibatkan tumpuan sepenuhnya (fully focus gathering) (pawagam, kulian/kelas, bank dan rumah ibadat) dengan tempat tumpuan pelbagai (multi focus gathering) (restoran, laluan pejalan kaki, pengangkutan awam dan pasaraya).

H8: Terdapat perbezaan penggunaan khidmat pesanan ringkas di antara tempat yang melibatkan tumpuan sepenuhnya (fully focus gathering) (pawagam, kulian/kelas, bank dan rumah ibadat) dengan tempat tumpuan pelbagai (multi focus gathering) (restoran, laluan pejalan kaki, pengangkutan awam dan pasaraya).

\subsection{KAEDAH KAJIAN}

\section{Kaedah Kutipan Data}

Kajian ini menggunakan kaedah tinjauan menggunakan soal selidik berstruktur. Sampel terdiri dari 400 orang responden yang terdiri daripada pelajar tempatan dan asing di sebuah universiti di utara Malaysia. Responden dari empat negara iaitu Malaysia, Indonesia, Iran dan China dipilih untuk terlibat dalam kajian ini kerana kelompok pelajar ini adalah antara yang tertinggi di universiti tersebut. Ini bagi memastikan jumlah responden bagi setiap kategori negara adalah mencukupi dan tidak terlalu kecil agar perbandingan dapat dilakukan. Penyelidik menetapkan pecahan responden kepada 100 orang untuk setiap kumpulan pengguna daripada budaya berbeza. Tiada had umur ditetapkan kerana penyelidik berpendapat pada masa kini telefon bimbit boleh dimiliki oleh sesiapa sahaja. Pemilihan saiz sampel telah dibuat berdasarkan prinsip 'Statistical Power for the behavioral sciences' oleh Cohen (1988). Menurut Cohen (1988) saiz sampel yang diperlukan $(\mathrm{d}=0.20, \alpha=0.05$, C.I. $=0.80)$ adalah 393. Oleh yang demikian, jumlah 400 responden bagi kajian ini adalah mencukupi.

\section{Kaedah Persampelan}

Kaedah persampelan yang digunakan adalah kaedah 'purposive sampling' dan juga kaedah 'snowball sampling' digunakan. Melalui teknik ini penyelidik menghubungi responden-responden berdasarkan negara yang dikehendaki oleh penyelidik dan seperti yang dicadangkan oleh pegawai di Pejabat Perhubungan Antarabangsa universiti tersebut. Responden ini kemudian akan membantu penyelidik mendapatkan reponden lain yang berasal dari negara yang sama dengannya.

\section{Instrumen kajian}

Terdapat empat pemboleh ubah utama dalam kajian ini iaitu persepsi terhadap penggunaan telefon bimbit di tempat awam, persepsi terhadap penggunaan khidmat pesanan ringkas di tempat awam, penggunaan telefon bimbit di tempat awam, penggunaan khidmat pesanan ringkas di tempat awam. Persepsi terhadap penggunaan telefon bimbit di tempat awam diukur dari sembilan soalan menggunakan Skala Likert lima mata dari sangat tidak setuju (1) kepada sangat setuju (5). Soalan-soalan yang digunakan adalah "Bunyi nada dering telefon bimbit semasa di pawagam akan mengganggu tumpuan penonton lain", Menjawab panggilan telefon bimbit di pasaraya boleh mengganggu orang lain semasa membeli belah", "Individu yang berbual menggunakan telefon bimbit di laluan pejalan kaki akan mengganggu orang lain yang menggunakan laluan tersebut", "Bunyi nada dering semasa sesi kuliah/kelas akan mengganggu tumpuan pelajar-pelajar lain 
semasa kuliah", "Berbual menggunakan telefon bimbit dalam restoran ketika makan bersama rakan akan menyebabkan rakan berasa tidak selesa", "Penggunaan telefon bimbit di rumah ibadat akan mengganggu konsentrasi orang yang beribadah", "Membuat panggilan telefon bimbit di dalam bas tidak akan mengganggu penumpang lain" (soalan yang dikod terbalik), "Berbual menggunakan telefon bimbit dalam restoran ketika makan berseorangan tidak akan mengganggu orang lain" (soalan yang dikod terbalik) dan "Menjawab panggilan telefon bimbit semasa berurusan di bank tidak akan mengganggu urusan orang lain" (soalan yang dikod terbalik).

Soalan yang hampir sama juga digunakan bagi mengukur persepsi terhadap penggunaan khidmat pesanan ringkas di tempat awam. Penggunaan telefon bimbit di tempat awam diukur Skala Likert empat mata dari tidak pernah (1) kepada sangat kerap (4). Antara soalan yang digunakan adalah "sejauhmanakah mereka membuat panggilan di lapan tempat berikut iaitu pawagam, dewan kuliah, restoran, bas/pengangkutan awam, pasaraya, laluan pejalan kaki, rumah ibadat dan bank". Soalan yang sama juga ditanya bagi penggunaan khidmat pesanan ringkas di tempat awam. Soalan-soalan diadaptasi daripada kajian Campbell (2007a). Hasil analisis kebolehpercayaan menunjukkan nilai alpha bagi kesemua pemboleh ubah adalah tinggi iaitu melebihi 0.7 .

\subsection{DAPATAN KAJIAN DAN PERBINCANGAN}

Ujian ANOVA Sehala digunakan untuk menentukan tahap perbezaan penggunaan telefon bimbit di tempat awam di kalangan responden dari empat negara iaitu Malaysia, Indonesia, Iran dan China. Hasil kajian menunjukkan wujud perbezaan yang signifikan antara responden dari negara berbeza $(\mathrm{F}=30.47, \mathrm{p}=0.000)$, di mana responden dari Indonesia didapati cenderung mempunya persepsi yang paling negatif terhadap penggunaan telefon di tempat awam $(\mathrm{M}=3.53)$, berbanding responden dari Iran yang lebih positif terhadap situasi tersebut $(\mathrm{M}=3.00)$. Sila rujuk Jadual 1 di bawah.

Seterusnya, ujian Post-Hoc Tukey HSD dilakukan untuk mengenalpasti perbezaan bagi setiap kumpulan negara. Hasil kajian menunjukkan perbezaan persepsi terhadap penggunaan telefon bimbit di tempat-tempat awam didapati wujud di kalangan responden Iran dan Malaysia, responden Iran dan Indonesia, responden Iran dan China dan responden Indonesia dengan responden China.

Jadual 1 Perbezaan persepsi terhadap penggunaan telefon bimbit dan khidmat pesanan ringkas di tempat awam ( $\mathrm{n}=400)$ dalam kalangan negara berbeza

\begin{tabular}{|c|c|c|c|c|c|}
\hline Pembolehubah & Negara & M1 & SP & $\mathbf{F}$ & $\mathbf{P}$ \\
\hline Persepsi terhadap & Malaysia & 3.33 & 0.42 & 30.47 & .000 \\
\hline Penggunaan telefon & Indonesia & 3.53 & 0.37 & & \\
\hline \multirow[t]{2}{*}{ Bimbit } & China & 3.21 & 0.35 & & \\
\hline & Iran & 3.00 & 0.38 & & \\
\hline Persepsi terhadap & Malaysia & 2.96 & 0.68 & 7.62 & .000 \\
\hline Penggunaan Khidmat & Indonesia & 2.98 & 0.64 & & \\
\hline \multirow[t]{2}{*}{ Pesanan Ringkas } & China & 2.90 & 0.72 & & \\
\hline & Iran & 2.60 & 0.51 & & \\
\hline \multicolumn{6}{|l|}{$\begin{array}{l}\text { Nota: Hasil ujian Post-Ho } \\
\text { a. Iran < Malaysia } \\
\text { b. Iran < Indonesia } \\
\text { c. Iran < China } \\
\text { d. Indonesia < China }\end{array}$} \\
\hline \multicolumn{6}{|c|}{$\begin{array}{l}\text { Nota: Hasil ujian Post-Hoc bagi persepsi penggunaan khidmat pesanan ringkas di tempat awam menunjukkan perbezaan antara kumpulan berikut: } \\
\text { a. Iran < Malaysia } \\
\text { b. Iran < Indonesia } \\
\text { c. } \quad \text { Iran < China }\end{array}$} \\
\hline
\end{tabular}

Seterusnya, analisis dilakukan bagi menentukan tahap perbezaan persepsi terhadap penggunaan khidmat pesanan ringkas di tempat awam di kalangan responden dari empat negara iaitu Malaysia, Indonesia, Iran dan China. Hasil kajian berdasarkan Jadual 1 menunjukkan wujud perbezaan yang signifikan antara responden dari negara berbeza $(\mathrm{F}=7.62, \mathrm{p}=0.000)$, di mana responden dari Indonesia $(\mathrm{M}=2.98)$ cenderung mempunyai persepsi yang paling negatif berbanding responden dari Iran $(\mathrm{M}=2.60)$.

Seterusnya, ujian Post-Hoc Tukey HSD dilakukan untuk mengenalpasti perbezaan bagi setiap kumpulan negara. Hasil kajian menunjukkan perbezaan persepsi terhadap penggunaan khidmat pesanan ringkas di tempat-tempat awam didapati wujud di kalangan responden Iran dan Malaysia, responden Iran dan Indonesia serta responden Iran dan China.

Bagi penggunaan telefon bimbit di tempat awam, hasil kajian berdasarkan Jadual 2 di bawah menunjukkan wujud perbezaan yang signifikan di antara responden dari negara berbeza $(\mathrm{F}=20.1, \mathrm{p}=0.000)$, di mana responden dari Iran cenderung menggunakan telefon bimbit di tempat awam $(\mathrm{M}=2.36)$ berbanding responden dari Indonesia $(\mathrm{M}=1.99)$ dan Malaysia (M=2.06). Manakala, ujian Post-Hoc Tukey HSD telah dilakukan untuk mengenalpasti perbezaan bagi setiap kumpulan negara. Hasil kajian menunjukkan terdapat perbezaan yang signifikan terhadap penggunaan telefon bimbit di tempat-tempat awam di kalangan responden Iran dengan responden dari Malaysia, Indonesia dan China. 
Jadual 2 Perbezaan penggunaan telefon bimbit dan khidmat pesanan ringkas di tempat awam $(n=400)$ dalam kalangan negara berbeza

\begin{tabular}{|c|c|c|c|c|c|}
\hline Pembolehubah & Negara & M1 & SP & $\mathbf{F}$ & $\mathbf{P}$ \\
\hline Penggunaan Telefon & Malaysia & 2.06 & 0.37 & 20.1 & .000 \\
\hline \multirow[t]{3}{*}{ Bimbit } & Indonesia & 1.99 & 0.32 & & \\
\hline & China & 2.14 & 0.32 & & \\
\hline & Iran & 2.36 & 0.42 & & \\
\hline Penggunaan Khidmat & Malaysia & 2.32 & 0.49 & 63.9 & .000 \\
\hline \multirow[t]{3}{*}{ Pesanan ringkas } & Indonesia & 2.17 & 0.32 & & \\
\hline & China & 2.30 & 0.33 & & \\
\hline & Iran & 2.97 & 0.59 & & \\
\hline
\end{tabular}

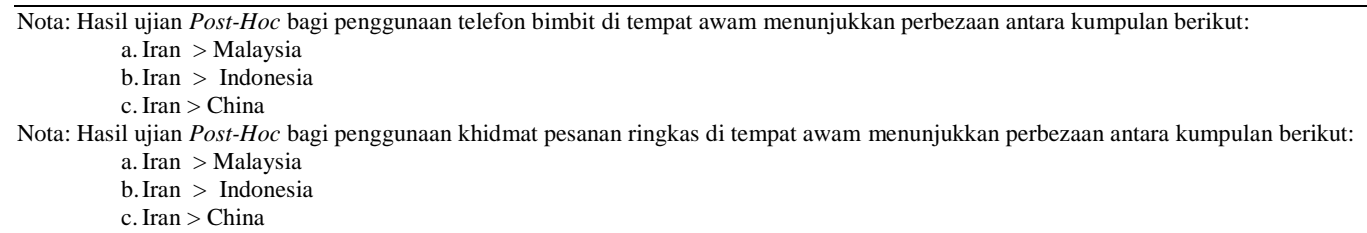

Manakala untuk menentukan tahap perbezaan penggunaan khidmat pesanan ringkas di tempat awam di kalangan responden dari empat negara, ujian ANOVA telah dilakukan. Hasil kajian berdasarkan Jadual 2 menunjukkan wujud perbezaan yang signifikan antara responden dari negara berbeza $(\mathrm{F}=63.9, \mathrm{p}=0.000)$, di mana responden dari Iran sekali lagi menunjukkan penggunaan khidmat pesanan ringkas yang paling tinggi di tempat awam $(M=2.97)$ berbanding responden dari Indonesia $(M=2.17)$, China $(M=2.30)$ dan Malaysia $(M=2.32)$. Ujian Post-Hoc Tukey HSD pula dilakukan untuk mengenalpasti perbezaan bagi setiap kumpulan negara. Merujuk kepada Jadual 2, perbezaan penggunaan khidmat pesanan ringkas di tempat-tempat awam didapati wujud di kalangan responden Iran dengan responden Malaysia, Indonesia serta responden China.

Seterusnya, Ujian Paired Sample t-test digunakan untuk menentukan perbezaan persepsi terhadap penggunaan telefon bimbit bagi tempat yang melibatkan tumpuan sepenuhnya (fully focused gathering) (pawagam, kulian/kelas, bank dan rumah ibadat) dengan tempat tumpuan pelbagai (multi focused gathering) (restoran, laluan pejalan kaki, pengangkutan awam dan pasaraya). Hasil kajian mendapati terdapat perbezaan yang signifikan dari segi persepsi terhadap penggunaan telefon bimbit di tempat awam bagi dua jenis tempat tersebut, $(\mathrm{t}=15.28$, $\mathrm{p}=0.000$ ), di mana responden lebih cenderung mempunyai persepsi yang negatif dalam penggunaan telefon bimbit di tempat tumpuan sepenuhnya $(\min =2.72)$ berbanding tempat yang melibatkan tumpuan pelbagai $(\min =1.82)$. Lihat Jadual 3 di bawah.

Jadual 3 Perbezaan persepsi terhadap penggunaan telefon bimbit dan khidmat pesanan ringkas mengikut tempat awam (N=400)

\begin{tabular}{|c|c|c|c|c|c|}
\hline Pembolehubah & Tempat Awam & Min & $\mathbf{S P}$ & $\mathbf{t}$ & $\mathbf{P}$ \\
\hline \multirow{3}{*}{$\begin{array}{l}\text { Persepsi terhadap } \\
\text { Penggunaan telefon } \\
\text { Bimbit }\end{array}$} & $\begin{array}{llll}\text { Tempat } & \text { Tumpuan } & \text { Sepenuhnya } & \text { (Fully }\end{array}$ & 2.72 & 1.05 & 15.28 & $.000^{*}$ \\
\hline & Focused) & & & & \\
\hline & Tempat Tumpuan Pelbagai (Multi-focused) & 1.82 & 0.67 & & \\
\hline Persepsi terhadap & Tempat Tumpuan Sepenuhnya & 2.31 & 0.89 & 10.40 & $.000 *$ \\
\hline Penggunaan Khidmat & Focused) & & & & \\
\hline Pesanan Ringkas & Tempat Tumpuan Pelbagai (Multi-focused) & 1.89 & 0.70 & & \\
\hline
\end{tabular}

Seterusnya, untuk menentukan perbezaan persepsi terhadap penggunaan khidmat pesanan ringkas bagi tempat yang melibatkan tumpuan sepenuhnya (fully focused gathering) dengan tempat tumpuan pelbagai (multi focused gathering), ujian Paired Sample t-test telah digunakan. Hasil kajian berdasarkan Jadual 3 mendapati terdapat perbezaan yang signifikan dari segi persepsi terhadap penggunaan khidmat pesanan ringkas di tempat awam bagi dua jenis tempat tersebut $(\mathrm{t}=-10.40, \mathrm{p}=0.000)$, di mana responden lebih cenderung mempunyai persepsi yang negatif dalam penggunaan khidmat pesanan ringkas di tempat tumpuan sepenuhnya (min=2.31) berbanding tempat yang melibatkan tumpuan pelbagai $(\min =1.89)$.

Seterusnya, untuk menentukan perbezaan penggunaan telefon bimbit bagi tempat yang melibatkan tumpuan sepenuhnya (fully focused gathering) dengan tempat tumpuan pelbagai (multi focused gathering), hasil kajian mendapati terdapat perbezaan yang signifikan dari segi penggunaan telefon bimbit di tempat awam bagi dua jenis tempat tersebut ( $\mathrm{t}=-23.42, \mathrm{p}=0.000$ ), di mana responden lebih cenderung menggunakan telefon bimbit di tempat tumpuan pelbagai $(\min =2.48)$ berbanding tempat yang melibatkan tumpuan sepenuhnya $(\min =1.79)$. Lihat Jadual 4 di bawah. 
Jadual 4 Perbezaan penggunaan telefon bimbit dan khidmat pesanan ringkas mengikut tempat awam $(\mathrm{N}=400)$

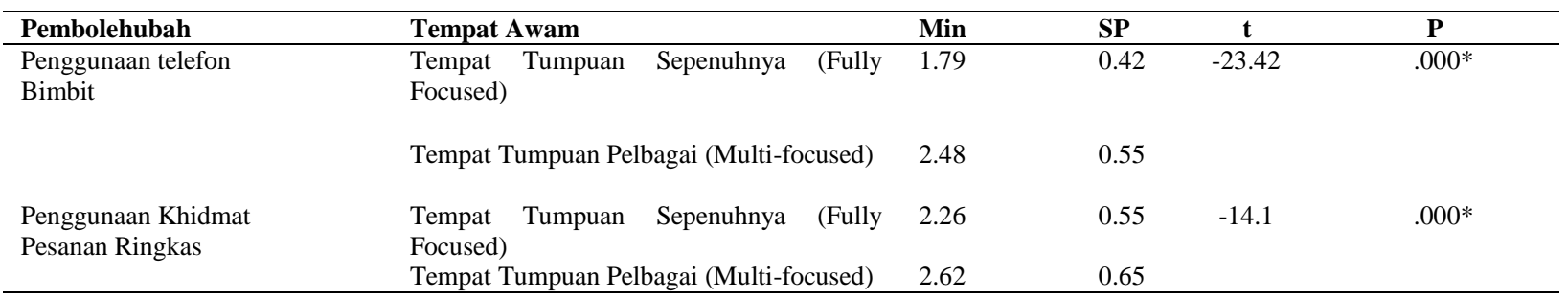

Hasil kajian yang terakhir adalah untuk melihat perbezaan penggunaan khidmat pesanan ringkas bagi tempat yang melibatkan tumpuan sepenuhnya (fully focused gathering) dengan tempat tumpuan pelbagai (multi focused gathering). Hasil kajian berdasarkan Jadual 4 mendapati terdapat perbezaan yang signifikan dari segi penggunaan khidmat pesanan ringkas di tempat awam bagi dua jenis tempat tersebut, ( $\mathrm{t}=-14.1, \mathrm{p}=0.000)$, di mana responden lebih cenderung menggunakan khidmat pesanan ringkas di tempat tumpuan pelbagai $(\min =2.62)$ berbanding tempat yang melibatkan tumpuan sepenuhnya $(\min =2.26)$.

\subsection{RUMUSAN}

Secara umumnya hasil kajian menunjukkan perbezaan yang signifikan di antara responden negara Iran dengan responden negara-negara lain (Malaysia, Indonesia, China) tentang persepsi dan penggunaan telefon bimbit dan khidmat pesanan ringkas di tempat-tempat awam. Responden Iran dilihat kerap menggunakan telefon bimbit dan khidmat pesanan ringkas di tempat awam berbanding dengan respondenresponden lain. Malah responden Iran juga yang paling kurang terganggu dengan penggunaan telefon bimbit dan khidmat pesanan ringkas di tempat awam. Bagi responden Malaysia, Indonesia dan China, mereka terganggu dengan penggunaan telefon bimbit dan khidmat pesanan ringkas di tempat-tempat awam. Ketiga-tiga kumpulan responden ini juga merupakan yang tidak kerap menggunakan telefon bimbit dan khidmat pesanan ringkas di tempat awam.

Kebanyakan responden Malaysia, Indonesia, China dan Iran lebih terganggu dengan penggunaan telefon dan khidmat pesanan ringkas di tempat tumpuan sepenuhnya, tetapi lebih bertolak ansur dengan penggunaan telefon dan khidmat pesanan ringkas di tempat tumpuan pelbagai. Ini bererti responden-responden ini lebih terganggu dengan penggunaan telefon bimbit dalam dewan kuliah, rumah ibadat, bank dan pawangam berbanding di dalam bus, laluan perjalanan kaki, pasaraya dan restoran. Responden-responden ini juga lebih kerap menggunakan telefon bimbit di tempat tumpuan pelbagai (multi focused) berbanding di tempat yang melibatkan tumpuan sepenuhnya (fully focused).

Hasil kajian ini menyokong dapatan kajian Campbell (2007a), iaitu masyarakat lebih cenderung untuk menolak penggunaan telefon bimbit di dalam kelas atau pawagam (fully focused gathering) berbanding tempat seperti restoran (partially focused gathering/multi focused gathering). Seiring dengan Teori Interaksi Sosial Goffman (1963) yang menyatakan bahawa dalam situasi tumpuan penuh seperti mesyuarat, aktiviti yang sedang berlangsung memerlukan penglibatan penuh individu yang berada di tempat tersebut. Deringan telefon atau perbualan telefon semasa mesyuarat berlangsung, menyebabkan orang di sekeliling merasa tersisih atau terganggu kerana ruang sosial mereka telah dicerobohi (Nickerson, Isaac \& Mak, 2008; Goffman, 1963 \& 1971). Deringan atau tindakan menjawab panggilan telefon ini menyebab individu lain dalam mesyuarat tersebut berasa marah, kerana tindakan ini mengganggu interaksi sosial mereka dalam mesyuarat tersebut Menurut Goffman (1971), panggilan telefon mengganggu interaksi bersemuka dan menyebabkan orang di sekeliling merasa terasing. Pada masa yang sama, orang di sekeliling juga perlu menghormati norma masyarakat seperti berpura-pura tidak mencuri dengar perbualan telefon tersebut (Humphreys, 2005).

Menurut Teori Interaksi Sosial, dalam perlakuan normatif berdasarkan nilai-nilai etika dan moral, individu yang menggunakan telefon di tempat awam contohnya dalam mesyuarat sepatutnya cuba mengimbangi pentas hadapan (orang awam di sekeliling) dengan pentas belakang (aktiviti menggunakan telefon bimbit atau aktiviti berbual dengan rakan melalui telefon) (Goffman, 1963). Ia satu perkara yang sukar kerana individu tersebut perlu mengimbangi dua aktiviti dalam satu masa iaitu konteks mesyuarat yang sedang berjalan dan konteks perbualan telefon yang sedang berlangsung. Sekiranya individu ini tidak berupaya mengimbanginya, maka akan wujud konflik, iaitu perasaan individu lain yang terganggu oleh perbualan telefon bimbit tersebut kerana penerima panggilan telefon tersebut terpaksa meninggalkan situasi sosialnya (mesyuarat) (Plant, 2001). Justeru itu, dapatan kajian ini jelas menunjukkan bahawa masyarakat lebih cenderung menolak penggunaan telefon bimbit di lokasi tumpuan penuh berbanding lokasi tumpuan pelbagai kerana perbuatan ini bertentangan dengan nilai etika dan perlakuan normatif masyarakat setempat.

Hasil kajian ini mempunyai persamaan dengan hasil kajian di Jepun, di mana penduduk Jepun mempunyai sifat lebih terbuka terhadap penggunaan khidmat pesanan ringkas berbanding membuat panggilan di tempat awam, akan tetapi tetap merasa terganggu dengan penggunaan ini di tempat tumpuan sepenuhnya dan mereka menunjukkan rasa tidak puas hati (Ito dan Okabe, 2005). Walaupun penggunaan khidmat pesanan ringkas di tempat awam terutamanya di tempat yang melibatkan tumpuan sepenuhnya (fully focused) dianggap mengganggu, ia adalah satu bentuk usaha untuk menghormati orang sekeliling oleh sesetengah pengguna telefon bimbit. Penggunaan khidmat pesanan ringkas ialah satu cara yang senyap dan mudah untuk mengekalkan interaksi sosial (Oksman dan Turtiainen, 2004) menjadikannya satu cara yang 'sopan' berbanding membuat atau menerima panggilan di tempat awam (Ito dan Okabe, 2005).

Selain itu, kajian turut mendapati bahawa responden Malaysia dan Indonesia menunjukkan paling banyak persamaan dalam persepsi terhadap penggunaan telefon bimbit di tempat awam. Faktor kedudukan geografi dan budaya mungkin mempengaruhi persamaan ini. Campbell (2007a) menyatakan terdapat kebarangkalian untuk responden yang berasal dari negara 'berbeza tetapi berdekatan' mempunyai persepsi yang sama kerana pengaruh budaya yang hampir sama. Menurut Goffman (1963) corak penglibatan dalam sesuatu interaksi sosial memerlukan konsensus dalam masyarakat. Budaya masyarakat seterusnya menentukan nilai, norma dan amalan yang diterima pakai dalam sesuai situasi. Dalam konteks penggunaan telefon bimbit, kedekatan budaya antara masyarakat Malaysia dan 
Indonesia mempengaruhi nilai dan perlakuan normatif dalam penggunaan telefon di tempat awam berbanding masyarakat di negara lain. Dalam kajian ini, responden Iran tidak merasakan bahawa perlakuan menggunakan telefon bimbit di tempat awam seperti dalam bilik mesyuarat dan bas sebagai sesuatu yang menyalahi norma dan budaya mereka kerana ini mungkin adalah amalan biasa di negara mereka.

Ini menunjukkan perbezaan negara juga menjadi faktor perbezaan dalam penggunaan telefon bimbit, sekaligus menyokong dapatan kajian-kajian terdahulu seperti Plant (2001) dan Nickerson, Isaac \& Mak (2008). Keadaan sosio budaya yang berbeza di antara negara membentuk corak penggunaan dan penerimaan telefon bimbit yang berbeza (Plant, 2001). Selain itu, konsep reka bentuk sesebuah tempat awam boleh menjadi galakan terhadap pengunaan telefon bimbit (Ling, 2004).

Walaupun semua responden (Malaysia, Indonesia, Iran, China) tahu tentang tempat-tempat yang dilarang penggunaan telefon bimbit, didapati responden tetap melanggar peraturan yang ditetapkan. Menurut Caronia \& Caron (2004), penggunaan telefon bimbit yang dahulunya bersifat peribadi kini 'dihalalkan' penggunaannya di tempat awam. Walaupun terdapat kemungkinan responden akan terbawabawa dengan peraturan yang telah ditetapkan di negara mereka semasa mereka berada di luar negara (Campbell, 2007b), perkara ini tidak ditunjukkan oleh responden Malaysia yang masih menggunakan telefon bimbit di kawasan larangan.

Secara umumnya, hasil dapatan kajian ini menyokong Teori Interaksi Sosial oleh Goffman (1963) yang menyatakan bahawa dalam situasi yang tidak memerlukan fokus penuh secara kolektif, penggunaan telefon bimbit adalah lebih diterima oleh masyarakat (Campbell, 2006). Kajian ini merumuskan bahawa masyarakat lebih cenderung mengguna dan menerima penggunaan telefon bimbit di tempat tumpuan pelbagai berbanding di tempat tumpuan penuh. Kajian juga merumuskan bahawa fakor kedekatan budaya dan geografi didapati mempengaruhi persepsi dan penggunaan telefon bimbit dan khidmat pesanan ringkas di tempat-tempat awam di mana didapati responden Iran dilihat kerap menggunakan telefon bimbit dan khidmat pesanan ringkas di tempat awam berbanding dengan respondenresponden dari negara-negara yang mempunyai budaya ketimuran yang sama iaitu Malaysia, Indonesia dan China.

Berikut pula adalah cadangan yang dicadangkan penyelidik untuk menambah baik kajian ini sekiranya ia dilakukan pada masa depan. Kajian ini hanya melihat perbezaan negara responden dalam persepsi dan penggunaan telefon bimbit di tempat awam. Untuk kajian akan datang faktor seperti taraf pendidikan, jantina dan taraf sosioekonomi perlu diambil kira dalam menilai persepsi dan penggunaan medium tersebut di tempat-tempat awam.

Selain itu untuk melihat secara langsung persepsi dan penggunaan telefon bimbit di tempat awam, penyelidik mencadangkan agar kaedah pemerhatian turut digunakan. Dengan menggunakan kaedah ini penyelidik berpeluang untuk melihat sendiri corak penggunaan telefon bimbit di tempat awam seperti kajian yang telah dijalankan oleh Humphreys (2005).

Selain itu, seiring perkembangan teknologi, pengkaji yang ingin mengkaji persepsi dan penggunaan telefon bimbit di tempat awam, juga perlu mengambil kira aplikasi lain yang turut terdapat di dalam telefon bimbit seperti aplikasi menonton video dan melayari Internet, bukan sekadar untuk membuat panggilan dan khidmat pesanan ringkas sahaja.

\section{Rujukan}

Campbell, S. W. (2007a). Perceptions of Mobile Phone Use in Public Settings: A Cross-Cultural Comparison. International Journal of Communication, 1(1), 738757.

Campbell, S. W. (2007b). A Cross-cultural Comparison of Perceptions and Uses of Mobile Telephony. New Media and Society, 9(2), 343-363.

Campbell, S. W. (2008). Perception of Mobile Phone Use in Public: The Role of Individualism, Collectivism and Focus of the Setting. Communication Reports, 21(2), $70-81$

Caporael, L. R., dan Xie, B. (2003). Breaking Time and Place: Mobile Technologies and Reconstituted Identities. New Brunswick, NJ: Transaction Publishers.

Caronia, L. , dan Caron, A. H. (2004). Constructing a Specific Culture: Young People's Use of the Mobile Phone as a Social Performance. Convergence, 10(2), 2861.

Chan, S., D. Vogel., dan Ma, L. C. K. (2007). Mobile Phone Communication Innovation in Multiple Time and Space Zones: The Case of Hong Kong Culture. Journal of Global Information Management, 15(4), 79-85.

Cohen J. (1988). Statistical Power Analysis for the Behavioral Sciences. New Jersey: Lawrence Erlbaum.

Fortunati, L. (2003). The Mobile Phone and Self-Presentation. Kertas dibentangkan dalam Front Stage/Back Stage: Mobile Communication and the Renegotiation of the Social Sphere Conference, Grimstad.

Goffman, E. (1971). Strategic Interaction. Philadelphia: University of Pennsylvania Press.

Goffman, E. (1959). The Presentation of Self in Everyday Life. Garden City, NY: Doubleday.

Goffman, E. (1963). Behavior in Public Places, New York: Free Press

Hall, E.T. (1959). The Silent Language, New York: Doubleday

Handphone Users Survey 2014. (2015). Cyberjaya, Selangor Darul Ehsan: Suruhanjaya Komunikasi dan Multimedia Malaysia. Diakses dari https://www.mcmc.gov.my/skmmgovmy/media/General/pdf/MCMC-Hand-Phone-User19112015.pdf pada 10 Oktober 2017

Humphreys, L. (2005). Cellphones in Public: Social Interactions in a Wireless Era. New Media Society, 7(6), 810-833

Ito, M., dan Okabe, D. (2005). Technosocial Situations: Emergent Structuring of Mobile E-mail Use. Dalam M. Ito, D. Okabe dan M. Matsuda (eds.). Personal, Portable, Pedestrian: Mobile Phones in Japanese Life, ms. 257-273. Cambridge, MA: MIT Press.

Katz, J. E., dan Aakhus, M. (2007) (Eds.). Perpetual contact. New York, Cambridge: Cambridge University Press.

Ling, R.(2004). The Mobile Connection: The Cell Phone's Impact on Society. San Francisco: Morgan Kaufman Publishers.

Love, S., dan Kewley, J. (2005). Does Personality Affect Peoples' Attitude Towards Mobile Phone Use in Public Places? Dalam R. Ling dan P. Pedersen (eds.). Mobile Communications: Re-negotiation of the Social Sphere, 40 (1), 1-22.

Monk, A., Fellas, E., dan Ley, E. (2004). Hearing Only One Side of Normal and Mobile Phone Conversations. Behaviour and Information Technology, 23 (5), 301305.

Nickerson, R. C., Isaac, H., dan Mak, B. (2008). A Multi-National Study of Attitudes About Mobile Phone Use in Social Settings. International Journal of Mobile Communications, 6(5), 541-563.

Oksman, V., dan Turtiainen, J. (2004). Mobile Communication as a Social Stage: Meanings of Mobile Communication in Everyday Life among Teenagers in Finland. New Media Society, 6 (3), 319-339.

Plant, S. (2001). On the Mobile: The Effects of Mobile Telephones on Social and Individual Life. Motorola, Diakses dari http://www.motorola.com/mot/documents/0,1028,296,00.pdf pada 6 Disember 2016

Sari, R.F., Ramli, K., dan Budiarjo, B. (2004). Mobile Communications Use in Indonesia: Case Study on Globalization and Localization Factor. Kertas dibentangkan dalam International Conference of Volunteers, Depok, Indonesia.

Wei, R., dan Leung, L. (1999). The Gratifications of Pager Use: Sociability, Information-seeking, Entertainment, Utility, and Fashion and Status. Telematics and Informatics, 5(5), 253-264. 